\title{
Site selection for scaled open water testing of a wave energy converter
}

\author{
Niall D. McLean, Matthew A. Holland, Ruairi D. Maciver and Elva B. Bannon
}

\begin{abstract}
Many wave energy converter developers opt to carry out scaled prototype open water testing of their device as part of their technology development. Developers who have done this recently include Sea Power (1/5 scale, Galway Bay, 2017), CorPower (1/4 scale, EMEC, 2018) and Marine Power Systems (1/4 scale, FaBTest, ongoing). Scaled open water testing offers several benefits, including more representative realisations of sub-systems, identification and resolution of technological issues associated with scaling-up, and de-risking the manufacturing and marine operational procedures ahead of commercial-scale testing. In preparation for testing in Stage 3 of the Novel Wave Energy Converter programme, Wave Energy Scotland has considered requirements of a suitable scaled open water site and the methods for selection. In common with commercial site identification, this must consider operational infrastructure, time and funding constraints, and the appropriateness of site characteristics. This appropriateness is further complicated by the need to find a site of comparable scaled water depth and where the sea-states of interest (when scaled to full-scale) are likely to occur with sufficient frequency over the duration of the intended testing campaign. This paper presents an approach, and its associated assumptions, to identify locations which have the potential to satisfy the scaled open water site considerations, before discussing the challenges to satisfy the critical testing outcomes, and the pragmatism required to meet all requirements.
\end{abstract}

Keywords- Open water, Scale WEC testing, Site selection.

\section{INTRODUCTION}

CALE prototype testing of wave energy converters $\mathcal{S}$ (WECs) in open water has become a recognized way of de-risking wave energy converters at technology readiness level (TRL) 5-6 ahead of construction of a commercial scale prototype. This is reflected by the number of developers now following this process and the establishment of many dedicated test centres for prototype testing. Along with this, technical specifications, such as those from the IEC [1], have been developed which

Manuscript received 16 March; accepted 26 March; published 8 Sept, 2020. This is an open access article distributed under the terms of the Creative $\begin{array}{lllll}\text { Commons Attribution } & 4.0 & \text { licence } & \text { (CC } & \text { BY }\end{array}$ https://creativecommons.org/licenses/by/4.0/). This article has been subject to single-blind peer review by a minimum of two reviewers. This work was funded by Wave Energy Scotland. address both the identification of suitable test sites, and, best practice for carrying out the tests.

Ref [1] advises that where possible scale WEC prototype testing in open water is done at an established test centre. The advantages of doing this include:

1) the test site is pre-consented;

2) the resource and other important environmental parameters tend to be well characterized;

3) relevant test infrastructure tends to be in place, including resource and other environmental condition measurements; and

4) the availability of experienced personnel, infrastructure and the local supply chain to support testing.

From a resource perspective, the suitability of a test site is dependent on how representative it is of the commercial site for which the technology is being designed. As such, a particular test centre may not always provide the most appropriate testing location for a technology developer.

In the past, requirements for consenting, power, and communication links, limited the locations where devices could be tested. However, recent technological developments in mobile test support infrastructure (MTSI), such as the EMEC test support buoys [2], greatly expands the range of locations where prototype testing can be carried out. MTSI of this type is typically equipped with:

1) umbilical cables which can connect the MTSI to the test device, allowing power transmission and communications between the two;

2) wireless technology which allows monitoring and control of the test device to be carried out remotely;

3) an onboard power supply to power both the MTSI functions and the test device;

4) power dissipation equipment which can emulate interaction with the grid; and

5) equipment which enables the MTSI to act as a navigational aid.

These capabilities make device testing possible at any location where wireless communication is available, safe installation and operation is feasible, and testing may be

N. McLean, M. Holland, R. Maciver and E. Bannon are at Wave Energy Scotland, An Lòchran, 10 Inverness Campus, Inverness IV2 5NA, UK (email: niall.mclean@waveenergyscotland.co.uk).

Digital Object Identifier https://doi.org/10.36688/imej.3.101-110 
permitted. Sites may therefore be selected that have the most relevant resource to match a developers' testing aims.

Participants in Stage 3 of Wave Energy Scotland's (WES's) novel wave energy converter programme (NWEC3) are expected to carry out open water testing of a scale prototype in Scottish waters over 6 months in 2020. Requirements of this activity are that:

1) the device is equipped with a power take-off (PTO) capable of generating electricity from extracted wave power, and providing behaviour/feedback that is representative of the intended commercial scale device's PTO; and

2) device performance measurements are made in a range of sea-states representative of those in which the commercial-scale device will generate power.

The scale required to accommodate a suitable PTO, and, the most relevant test sea-states, are recognized to be device specific. Therefore, the NWEC3 developers have been invited to select their own device scale and the most appropriate test site to meet these requirements.

To better understand the choices NWEC3 developers faced when selecting scale sites for WEC testing, WES has reviewed current best practice (given in [1] and [3]) and carried out a mock site selection exercise for a quarter-scale WEC using readily available wave resource data. This paper reports on this activity and on some interesting findings which arise. These include perspectives on:

1) the applicability of multi-criteria site selection (MCSS) for scale site identification, and what resource data is available to do this; and

2) the use of hindcast resource data from an oceanic scale spectral wave model to assess potential scale sites according to how well their scale resource matches with a commercial scale resource, for down-selecting purposes.

In the first case, a metric for scoring the suitability of a site's wave resource for scale testing in MCSS is postulated.

In the second case, some useful insight is gained on site suitability from the oceanic scale wave model hindcast data used, even though model spatial resolution is too coarse to accurately resolve the wave climate near to shore where scale WEC tests are likely to be located.

\section{SITE REQUIREMENTS}

The MCSS approach identified in [3] employs a multilayer Geographical Information System (GIS), with each GIS data layer scoring the suitability of sites across a region of interest against a specific criterion. For marine renewable device deployment, scored criteria typically fall into one of five categories: resource, environmental impact, test environment, other users and nearby infrastructure. After scores have been assembled for all criteria, the overall suitability of a site is assessed using a weighted sum of scores across all criteria, with the weighting for each criterion specified according to its relative importance. Readers interested to know more about MCSS are referred to [4], where it has been applied to identify suitable sites for floating offshore wind turbines in European waters.

MCSS would also seem to be applicable to identification of sites for scale WEC prototype testing. However, at the time of writing no studies doing this were readily available. This sparsity may be a result of the additional complexities of applying MCSS to scale site selection. These complexities include:

1) large variations in the wave resource along a coastline, requiring large volumes of data to be handled in MCSS for resource criteria;

2) site suitability from a resource perspective being based on comparison of one bivariate dataset with another, i.e. comparison of the prospective scale site's scatter table with that of the proposed commercial scale site; and,

3) resource matching being dependant on the particular device and test scale, as discussed in the Introduction.

\section{A. Multi criteria site selection scoring criteria}

A brief review of criteria of relevance to site selection for scale WEC prototype testing using MCSS, or more ad hoc methods, is presented here. Potential data sources for each of the five scoring criteria categories are presented in Table I. Pertinent site selection criteria related to the categories are presented in Table II. These criteria combine those given by [1], [3], and some which the present authors believe may be useful.

$$
\text { TABLE I }
$$

SUGGESTED DATA SOURCES FOR EACH CATEGORY IN A MCSS

\begin{tabular}{ll}
\hline Category & Data source \\
\hline Resource & $\begin{array}{l}\text { Appropriate measurements and/or } \\
\text { numerical model predicted wave data. } \\
\text { Predicted wave data should be from a } \\
\text { model with a sufficiently high spatial } \\
\text { resolution and which has been validated } \\
\text { with measurements [5]. }\end{array}$ \\
& GIS databases in common usage. \\
Infrastructure & $\begin{array}{l}\text { Admiralty charts, and marine } \\
\text { Test Environment }\end{array}$ \\
& Geotechnical data (e.g. from British \\
& Natura 2000 database [6]. \\
Environment Impact & AIS vessel tracking data [7]. \\
Other Users &
\end{tabular}


TABLE II

IMPORTANT CRITERIA FOR SELECTION OF A SCALE WEC TEST SITE

\begin{tabular}{lll}
\hline Criteria & Source & Category \\
\hline $\begin{array}{l}\text { Appropriate spatial and temporal } \\
\text { wave conditions in both amplitude } \\
\text { and period }\end{array}$ & {$[1]$} & Resource \\
& & \\
& & \\
$\begin{array}{l}\text { Appropriate water depth for wave } \\
\text { kinematic fidelity }\end{array}$ & $\begin{array}{l}\text { Paper } \\
\text { Authors }\end{array}$ & Resource \\
& Paper & Resource \\
Directional wave spectra & Authors & \\
&
\end{tabular}

Convenient launch and deployment facilities, and vessel availability

Local service and

maintenance amenities

Land-based data station

Appropriate water depth for mooring fidelity

Appropriate atmospheric and oceanographic conditions

Appropriate seabed conditions

Nature conservation areas

Marine habitats

Landscape

Supporting infrastructure

Other Users

Other site users

[3] Other Users

Test

Paper Test

Comment

Good coverage of relevant sea-states which, when scaled, fall into the energetic bins of a commercial site's scatter table, i.e., are likely to be used for power extraction. Sea-states outside this envelope may also be of interest for extreme sea testing, but they could have a bearing on the fidelity of scale testing as their presence may impact on the scale prototype design.

Wave kinematic effects may have an impact on testing if the influence of the sea bed on incident waves differs between scale and commercial-scale sites. (See e.g. [8])

It would be preferred to have sea-states at the scale site which have comparable directional spectra, $S(\omega, \theta)$, to scale, with the corresponding sea-states in the same scatter table bin at the commercial-scale site. Note: both [9] and [10] highlight errors in power capture estimation when assumed incident wave spectrum does not match the actual spectrum.

[1] Infrastructure -

[1] Infrastructure -

[1] Infrastructure If wireless communication with the device is feasible and reliable, it may possible to have this further away, e.g. using MTSI.

Environment

This makes it easier to define a scale mooring which has a comparable effect on the scale device to that expected for the commercial-scale device.

Such as the absence of rip currents, hurricanes, or excessive Environment suspended sediment.

Authors Environment

Seabed conditions will drive the choice of anchoring/foundation solution, e.g. the presence of sand on site would allow drag embedment anchors to be employed, which are a cost-effective anchoring solution.

Environmental Proximity to statutory and voluntary nature conservation areas Impact (both existing and planned Special Areas of Conservation, Special Protection Areas, SSSI, Marine Consultation Areas, etc.). Note that anything impacting on the environment is likely to require engagement in a consenting process. Developers must be cognisant of sensitivities, concerns, etc.

Environmental Considerations include the possible impact on benthic Impact habitats/marine ecology (including electro-sensitive species), intertidal habitats, fishing and aquaculture areas, marine mammals (cetaceans, seals, otters, etc.), birds, and the location of any noise sensitive receptors.

Environmental Considerations include the impact on coastal processes, marine Impact archaeology, aesthetic impacts on the seascape and other cumulative impacts.

Anything impacting on other users is likely to require engagement in a consenting process. Supporting infrastructure may include dredging (along with any associated dredged material /spoil disposal), pipelines and cabling. Impacts to consider include those on nature conservation, navigation, shipping routes, anchorages and port approaches.

Other site users to consider may include the military, commercial and recreational fisheries, recreational sailing and tourism, and archaeological and cultural heritage.
It should be noted that MCSS weights for each criterion are not provided here as these are invariably device and test objective specific. However, it is fair to assume that weightings for criteria in categories where testing has impacts on other users, or, on the environment will be higher, as these are likely to impact on the amount of 
consenting activity which will be necessary. It is also presumed in this review of selection criteria that no static or dynamic cabling is required from the device to shore, i.e. mobile test support infrastructure is employed. The need for cabling from the device to shore introduces additional requirements - see both [1] and [3].

The scale wave resource characterization presented here raises an interesting question, if a multi-criteria site selection exercise was performed to identify the appropriate sites for scale WEC testing, what wave data should be used? The most practical option for this would appear to be to use spectral wave models, given the expense of taking measurements. However, using a spectral wave model to resolve the nearshore wave climate over a large region at a sufficiently high resolution and over an appropriate duration, while managing all the data outputs for MCSS, is a challenging proposition.

\section{CASE STUDY}

\section{A. Approach}

A case study has been performed applying aspects of MCSS to understand if this is an acceptable way to investigate whether the resource at a prospective scale site offers good coverage, to scale, of the resource at a commercial-scale site to satisfy the testing requirements for NWEC3 [19].

Ideally such a case study would use measurement data of a suitable duration directly, or, a spectral wave model with sufficient spatial resolution to resolve nearshore wave effects and which has been validated against measurements as recommended in [5]. Examples of resource characterization modelling are available for the Galway Bay Test Site [11] and for the FabTest Test Site [12]. Generally, such data is not readily available.

The case study uses freely available hindcast $\left(H_{m 0}, T_{p}\right)$ data from the 30-year Phase 2 NOAA NCEP Wavewatch III hindcast (NOAA hindcast) [13]. Studies utilising this dataset to categorise parts of the nearshore environment in the UK and US for various WECs with different power ratings have recently published in [14] and [15] respectively. In this study, data from 2008 has been used.

Use of this data poses additional interesting questions:

1) Does an assessment of site suitability with data from a model which is too coarse to resolve nearshore wave transformations shed any light on the actual suitability of a site located in the nearshore environment, given this is where wave transformation effects such as shoaling, refraction, wave breaking and diffraction can occur?

2) Can data from a coarse model be used to down-select regions which can be subjected to a more detailed assessment using a model with a higher spatial resolution, or, measurements?

To assess how good a site is, it is assumed that a good scale site is one where a device developer can test in seastates which scale to the most energetic sea-state bins in a target commercial-scale site $\left(H_{m 0}, T_{p}\right)$ scatter table multiple times. In this case study, the commercial-scale site is taken as Billia Croo in Orkney and three potential regions have been assessed on their suitability to host a scale site based on these characteristics. The three regions, shown in Fig. 1, were selected as examples covering the variety of the wave resource in Scottish waters:

1) A region to the south of Arran in the Firth of Clyde, a semi-closed basin with a moderately sized southwest fetch;

2) A region to the north of Burghead in the Moray Firth, a large open estuary with long fetches in northnortheast to east directions and some shelter to the north; and

3) A region to the north of the Melvaig Peninsula in the Minch, a relatively narrow waterway between the Outer Hebrides and the mainland of Scotland with a long north fetch.

Details of the cells in the NOAA model representing the three potential scale site regions and Billia Croo, including the latitude and longitude of the centre of cell and the cell's water depth, are presented in Table III.

TABLE III

LOCATIONS OF REGIONS OF INTEREST

\begin{tabular}{|c|c|c|c|}
\hline \multirow[b]{2}{*}{ Region } & \multicolumn{2}{|c|}{ NOAA cell centre } & \multirow[b]{2}{*}{$\begin{array}{l}\text { NOAA cell depth } \\
(\mathrm{m})\end{array}$} \\
\hline & $\begin{array}{l}\text { Latitude } \\
\text { (WGS84) }\end{array}$ & $\begin{array}{c}\text { Longitude } \\
\text { (WGS84) }\end{array}$ & \\
\hline South Arran & $55^{\circ} 24^{\prime} \mathrm{N}$ & $5^{\circ} 12^{\prime} \mathrm{W}$ & 30.6 \\
\hline Burghead & $57^{\circ} 44^{\prime} \mathrm{N}$ & $3^{\circ} 28^{\prime} \mathrm{W}$ & 17.9 \\
\hline Melvaig Peninsula & $57^{\circ} 52^{\prime} \mathrm{N}$ & $5^{\circ} 44^{\prime} \mathrm{W}$ & 15.5 \\
\hline $\begin{array}{l}\text { Billia Croo } \\
\text { (commercial-scale) }\end{array}$ & $59^{\circ} 0^{\prime} \mathrm{N}$ & $3^{\circ} 28^{\prime} \mathrm{W}$ & 60.3 \\
\hline
\end{tabular}

\section{B. Assumptions}

The following assumptions have been made in the case study assessment:

1) A site with a comparable water depth, to scale, with the depth at the commercial-scale site (taken to be $60 \mathrm{~m}$ for Billia Croo) is available in each region considered and the sea-state predictions made for the corresponding NOAA hindcast cell are still relevant, even if the depth in NOAA hindcast cell is not comparable to scale with the depth at the commercial scale site.

2) The NOAA hindcast simulations are sufficiently accurate for assessment purposes.

3) For the purpose of estimating the incident power at the commercial-scale site for each sea-state bin, it is assumed that the incident sea-state has a JONSWAP spectrum with a peak enhancement factor $\gamma$ of 3.3 (this being the average value of the peak enhancement measured by Hasselmann et al. [16]) and the energy period $T_{m-10}$ can be estimated from the peak peak $T_{p}$ using the empirical formula,

$$
T_{m-10}=((4.2+\gamma) /(5+\gamma)) T_{p}
$$




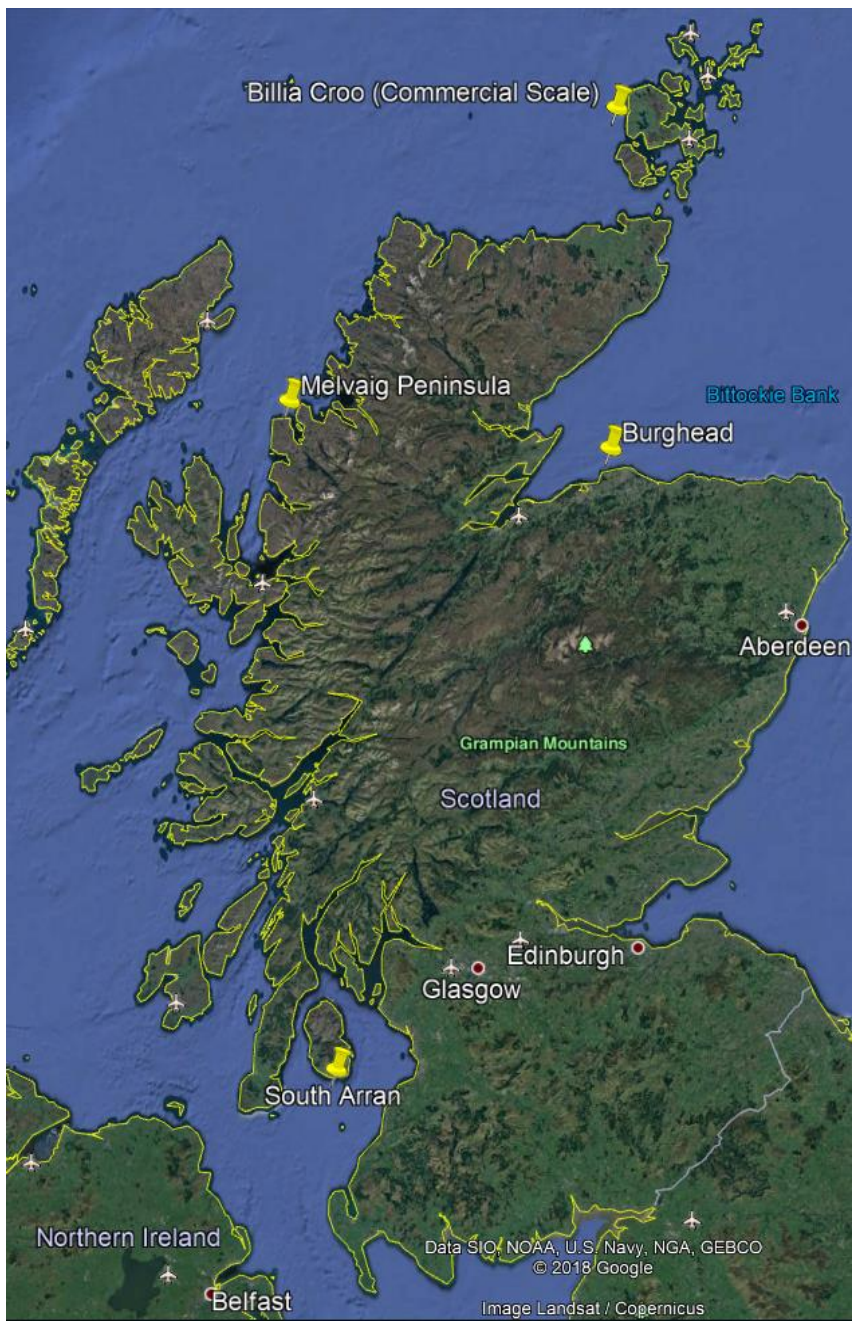

Fig 1. Location of regions (yellow pins) where suitability of resource for a scale site has been assessed.

4) The incident power $P$ for sea-states in each $\left(H_{m 0}, T_{p}\right)$ bin of the scatter table can be reasonably estimated, according to linear wave theory, with

$$
P=\frac{\rho g}{16} H_{m 0}^{2} c_{g}\left(\frac{(4.2+\gamma)}{(5+\gamma)} T_{p}, h\right)
$$

where $H_{m 0}$ and $T_{p}$ are the median significant wave height and median peak period for each scatter table bin and $c_{g}(T, h)$ is the group velocity for a regular wave with a period $T$ propagating across water with a depth of $h$. Note the use of (1) to estimate the energy period $T_{m-10}$ for each bin's median peak period.

5) The sea-state $\left(H_{m 0}, T_{p}\right)$ scatter for 2008 is reasonably representative of the scatter in other years. To increase the thoroughness of the assessment, both the annual variability and design envelope of the wave climate could also be considered (e.g. the 100 year IFORM contour as defined in [17]).

\section{Comparison Plots}

To assess the suitability of the regions, comparison plots have been prepared using the methodology described in Section III.A for selected periods of a 3-month duration throughout the year.
Comparison plots are presented for two 3-month periods for each region: South Arran (Section III.D.1); Burghead (Section III.D.2); and the Melvaig Peninsula (Section III.D.3). These time windows are indicative of the predicted resource characteristics during months when scale device testing might be undertaken.

\section{Analysis \\ 1) South Arran}

The comparison for the South Arran region is shown for the periods covering February to April 2008 and May to July 2008 in Fig. 2 and Fig. 3 respectively.

Over both time frames most of the scale site sea-states fall into scatter table bins on the leading edge. These seastates are typical of wind seas generated by the action of the wind on the sea surface on a closed basin, as might be expected at that location. A significant number of seastates with relatively high period $(>21 \mathrm{~s}$ at commercial device scale) and low significant wave height are observed. These occurrences are possibly exaggerated by lack of resolution of the Rhinns of Galloway in NOAA model (see Fig. 8 and Fig. 9) allowing longer period waves to propagate more freely into the Clyde from the Irish Sea than would occur in reality.

Considering the suitability of South Arran as a scale site, the comparison shown in Fig. 2 and Fig. 3 is not encouraging in two respects. Firstly, there is a lack of occurrences of sea-states with scaled $\left(H_{m 0}, T_{p}\right)$ statistics in the target bins. Secondly, there are a significant number of occurrences of scaled up sea-states with $\left(H_{m 0}, T_{p}\right)$ statistics outside the range of the commercial-scale site, which the scale test device would need to be designed to be able to be accommodate, assuming these are real phenomena. Fundamentally, any scale sea-states which fall outside the envelope of scatter table bins of the commercial-scale site can result in the need for test device components (such as moorings) which do not have comparable behaviour with the commercial-scale equivalent components.

It is possible that nearshore processes including refraction, shoaling, wave breaking and diffraction by coastline features acting on waves reaching this region are not well represented in the NOAA model, making the wave climate in this region more suitable as a quarter-scale site than the results presented here suggest. While this could be explored using spectral wave models with higher spatial resolution and/or in-situ measurements, low occurrences of sea-states in target bins with longer peak periods $\left(T_{p}\right)$ suggests this is not worthwhile for this site. 


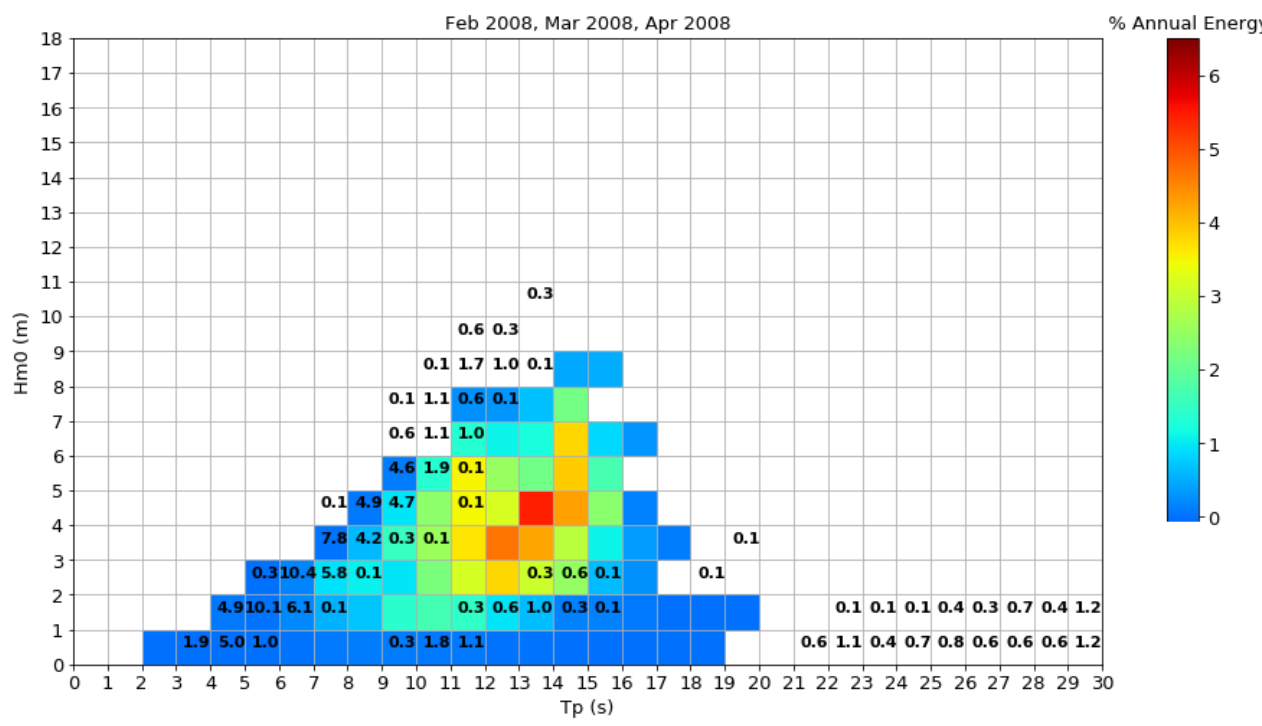

Fig 2. Scaled up South Arran $\left(H_{m 0}, T_{p}\right) \%$ occurrence scatter table (tabulated numbers) for Feb-Apr 2008 overlaid on Billia Croo $\left(H_{m 0}, T_{p}\right) \%$ annual incident energy scatter colour map for 2008.

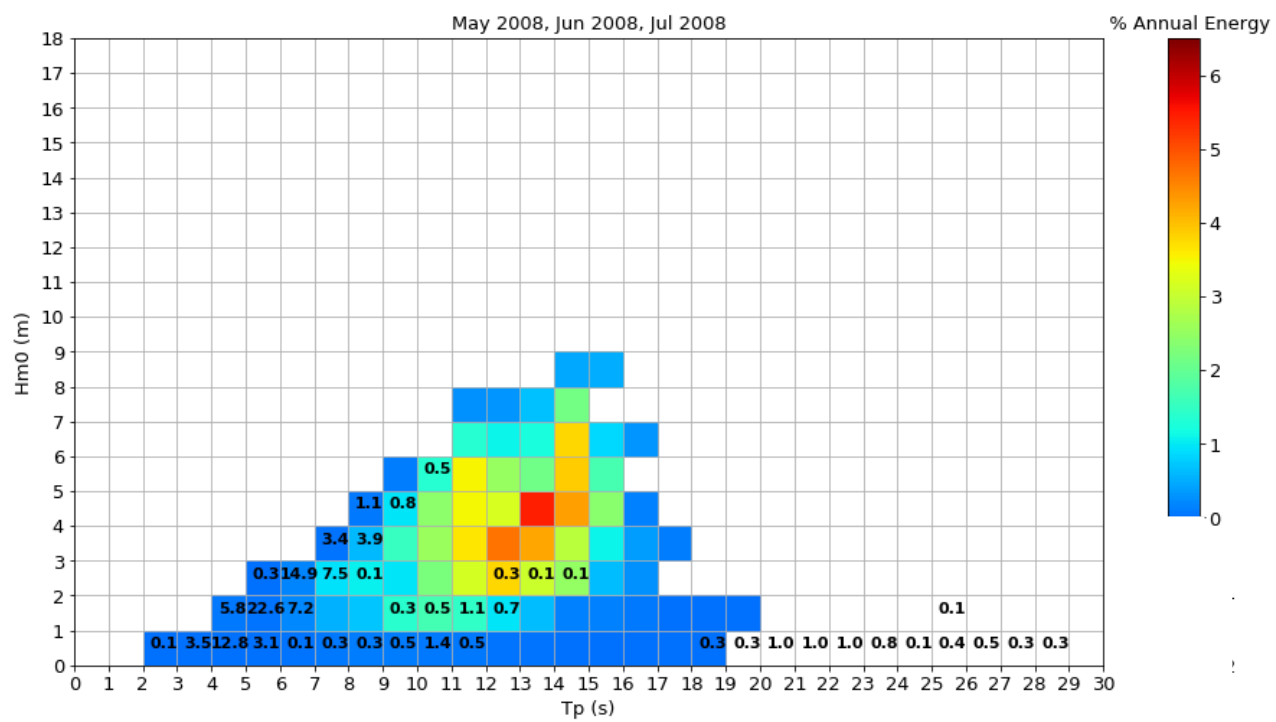

Fig 3. Scaled up South Arran $\left(H_{m 0}, T_{p}\right) \%$ occurrence scatter table (tabulated numbers) for May-Jul 2008 overlaid on Billia Croo $\left(H_{m 0}, T_{p}\right) \%$ annual incident energy scatter colour map for 2008.

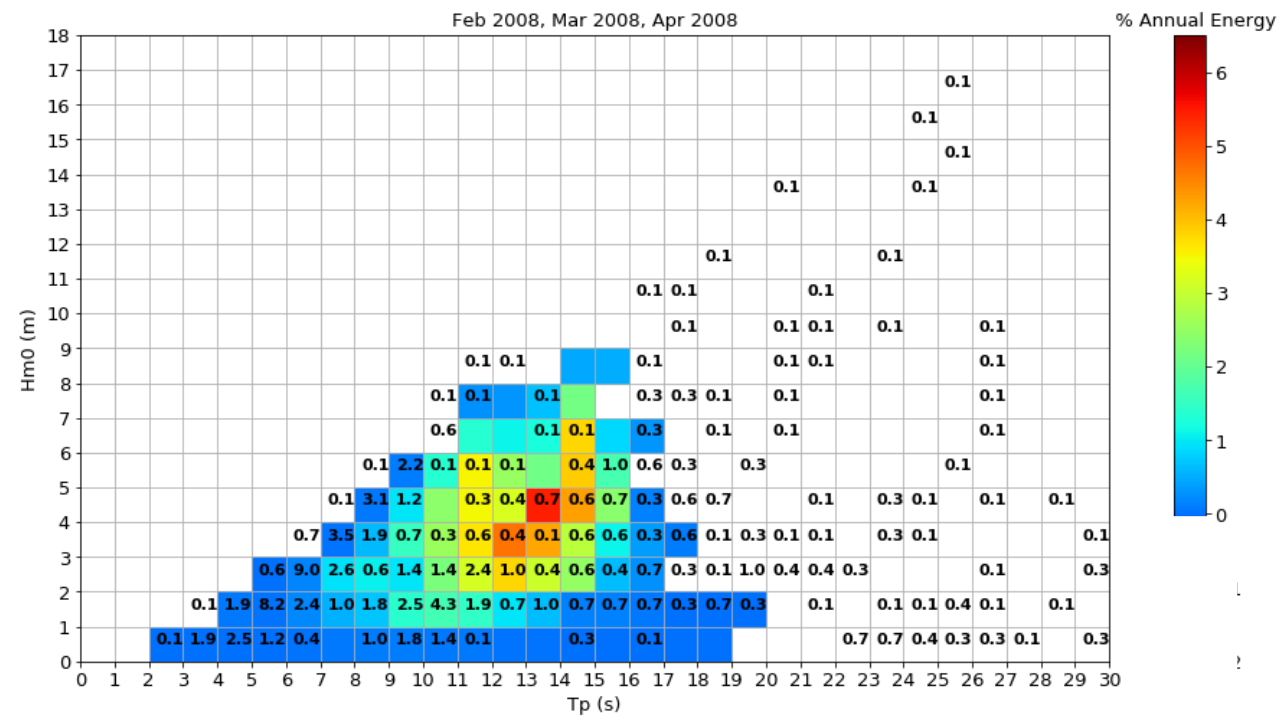

Fig 4. Scaled up Burghead $\left(H_{m 0}, T_{p}\right) \%$ occurrence scatter table (tabulated numbers) for Feb-Apr 2008 overlaid on Billia Croo $\left(H_{m 0}, T_{p}\right) \%$ annual incident energy scatter colour map for 2008. 


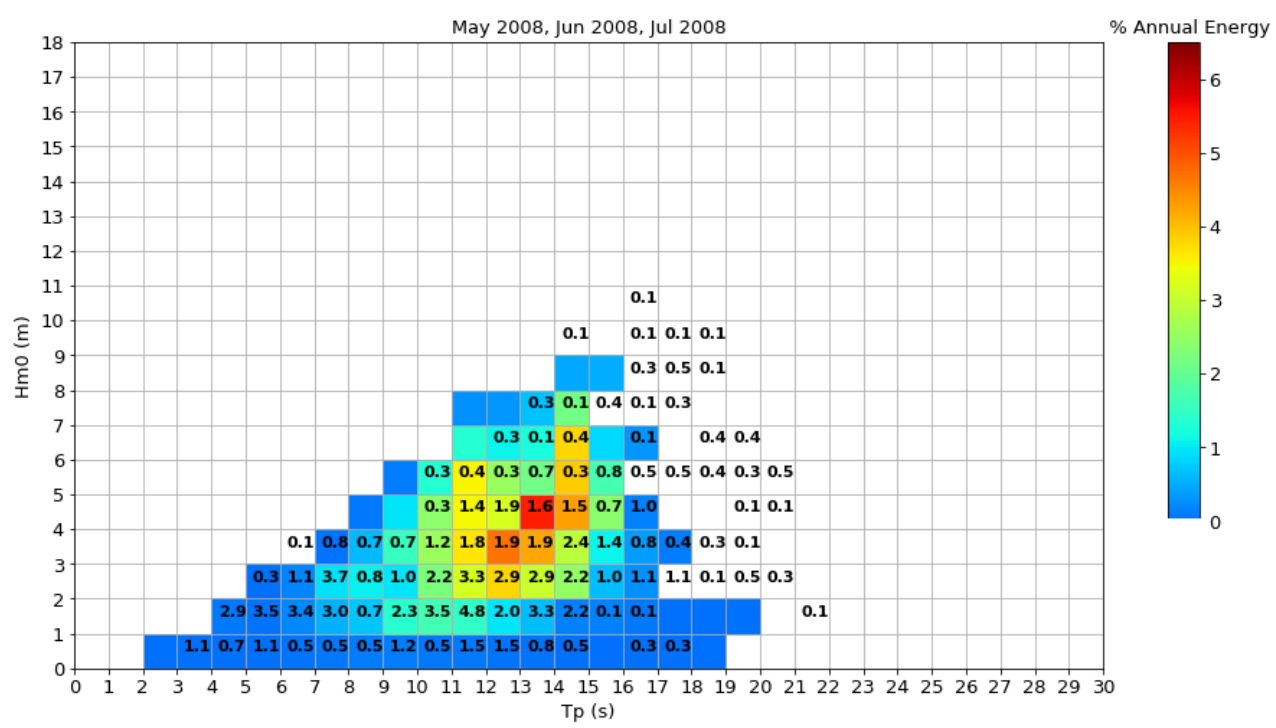

Fig 5. Scaled up Burghead $\left(H_{m 0}, T_{p}\right) \%$ occurrence scatter table (tabulated numbers) for May-Jul 2008 overlaid on Billia Croo $\left(H_{m 0}, T_{p}\right) \%$ annual incident energy scatter colour map for 2008.

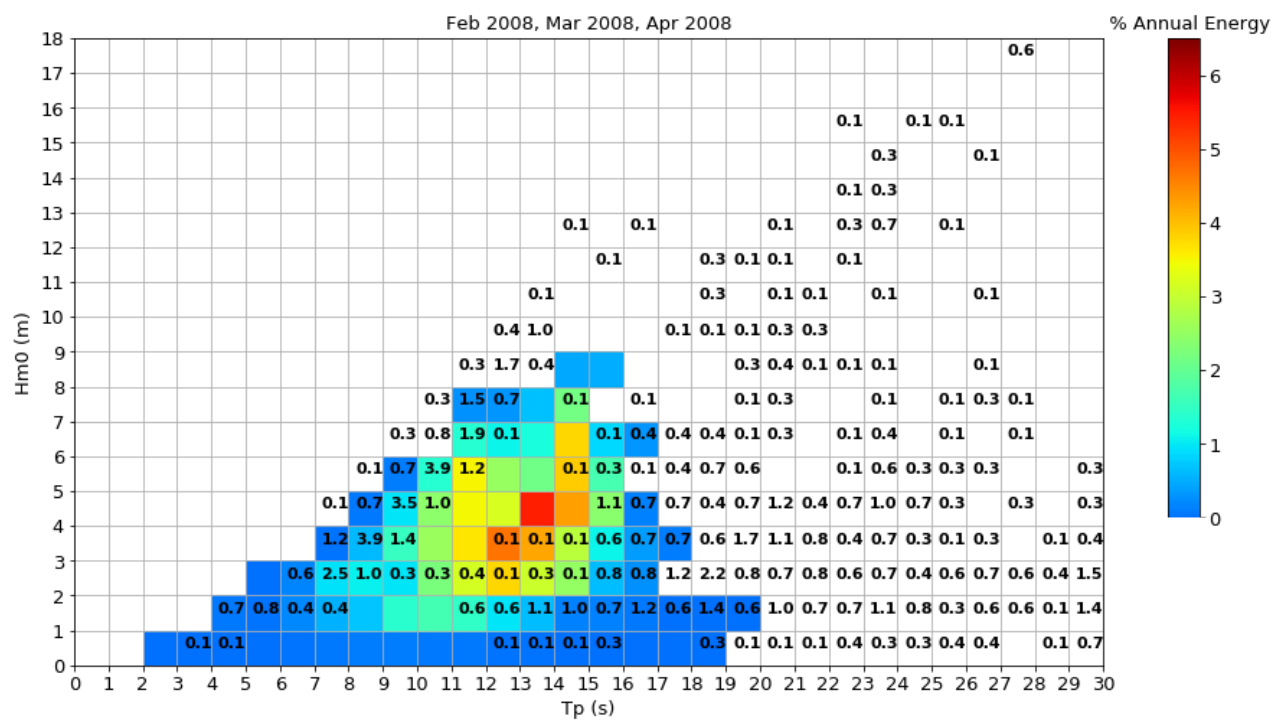

Fig 6. Scaled up Melvaig Peninsula $\left(H_{m 0}, T_{p}\right) \%$ occurrence scatter table (tabulated numbers) for Feb-Apr 2008 overlaid on Billia Croo $\left(H_{m 0}\right.$, $\left.T_{p}\right) \%$ annual incident energy scatter colour map for 2008.

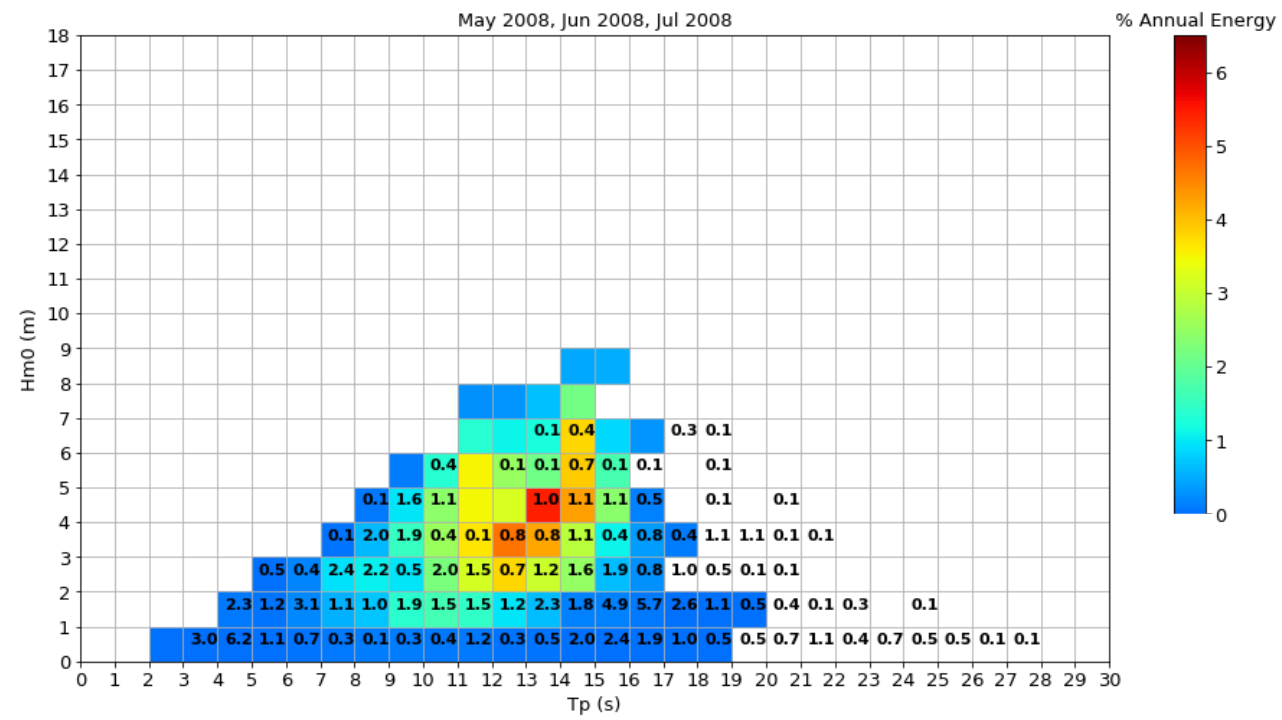

Fig 7. Scaled up Melvaig Peninsula $\left(H_{m 0}, T_{p}\right) \%$ occurrence scatter table (tabulated numbers) for May-Jul 2008 overlaid on Billia Croo $\left(H_{m 0}\right.$, $\left.T_{p}\right) \%$ annual incident energy scatter colour map for 2008. 


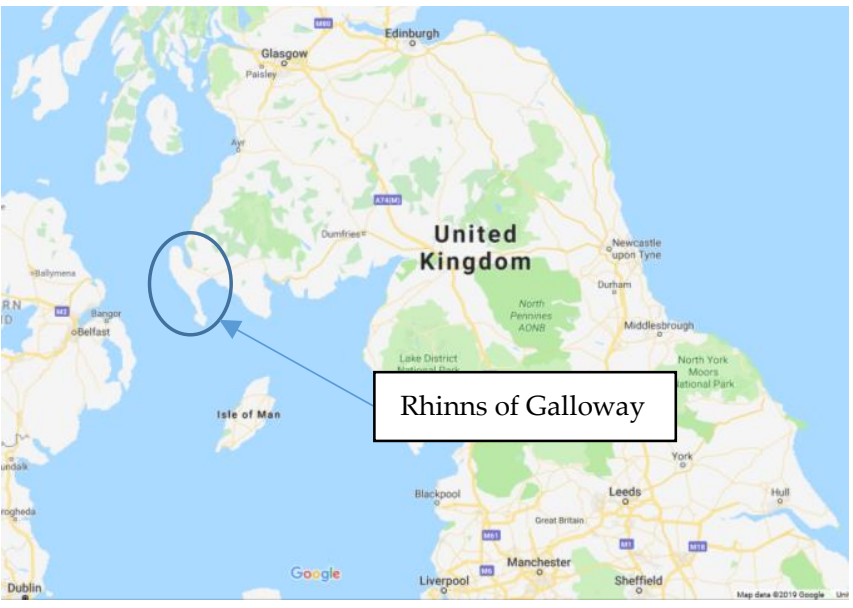

Fig. 8. The Scottish southwest coastline, as it is in reality.

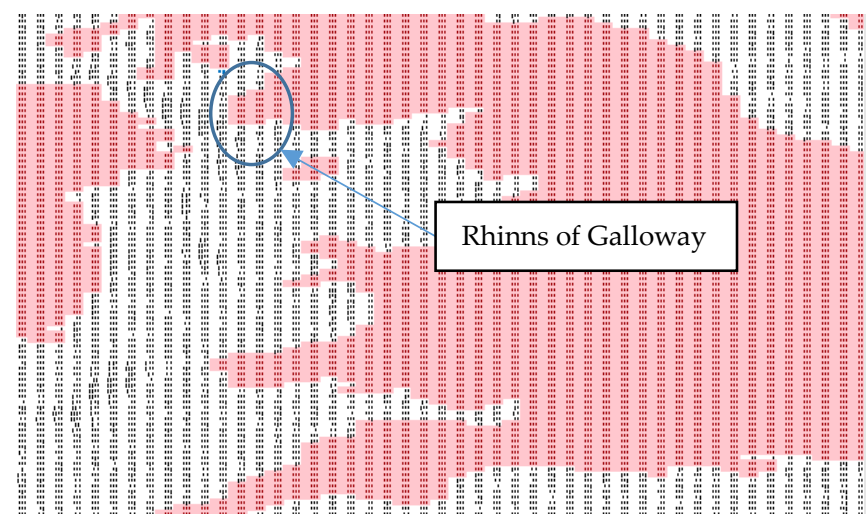

Fig. 9. Southwest Scotland, as represented in the NOAA model. Note, each element represents either a water cell (white) where the wave climate is predicted or a land cell (pink) where no wave climate predictions are made.

An alternative strategy for making use of the predicted resource in the South Arran region could to consider a device smaller than quarter-scale. This would potentially allow scale versions of the targeted sea-states from the commercial-scale site to be tested. However, it is unlikely that the change of scale would significantly expand the range of sea-states that could be tested, due to the relative narrow-bandedness of predominant wind sea $\left(H_{m 0}, T_{p}\right)$ scatter. An additional adverse side effect of a smaller scale would be to expose the device to more sea-states with scaled $\left(H_{m 0}, T_{p}\right)$ statistics outside the envelope of scatter table bins of the commercial-scale site, which can result in fidelity issues with the device design as discussed above.

\section{2) Burghead}

A significant proportion of the sea-states predicted to occur at Burghead, as shown in Fig. 5 and Fig. 6, are again dominated by wind seas, characterized by the steepest seastates on the leading edge of scatter table, as was seen with the South Arran wave climate. However, with the region's greater level of exposure, it experiences a greater proportion of swell dominated sea-states than the South Arran region.

From the perspective of the suitability of Burghead as a quarter-scale test site, the 2008 comparison suggests that seasonality has an important role. In particular, over the May to July 2008 period (Fig. 6) there is good coverage of sea-states which frequently occur at the target resource, and relatively limited occurrence of sea-states outside this range. This is in contrast to the February to April 2008 period (Fig. 4), where coverage of the target resource was good but there were a significantly greater proportion of sea-states larger than the targeted range of conditions. Nevertheless, it is encouraging to find a region where for at least part of one year, good coverage of target sea-state bins was seen.

\section{3) Melvaig Peninsula}

Results from the comparison for Mevaig Peninsula (Fig. 6 and Fig. 7) are fairly similar to those for Burghead. During February to April (Fig. 6) the conditions appear too rough, with sea-states outside the range of frequently occurring seas at the targeted commercial-scale site. However, the May to July period (Fig. 7) shows a good fit to the range of populated sea-state bins from the commercial site's scatter table. There are fewer extremes of wave height $\left(H_{m o}\right)$ predicted during this period than at Burghead, but a higher number of longer period $\left(T_{p}\right)$ seastates outside the target range.

\section{E. Limitations}

The principal limitation of the approach proposed here is that the hindcast data is from a relatively coarse model with a relatively coarse spatial resolution. Cells in Scottish waters within the NOAA hindcast model are around 7.6 $\mathrm{km}(\mathrm{E}) \times 7.4 \mathrm{~km}(\mathrm{~N})$, which means the nearshore bathymetry and coastline shape is not well resolved and their influence on the nearshore wave climate will be poorly represented. Note, the IEC guidance on wave resource modelling [5] suggests a water depth threshold of $16 \mathrm{~m}$, below which nearshore effects on the wave resource should be considered. The water depth for all of the regions considered here are around this value, as indicated in Table III.

Further limitations to the approach presented here include:

1) No consideration of wave-current interactions is included in the NOAA hindcast data used.

2) Model outputs $\left(H_{m 0}, T_{p}\right)$ are short-term sea-state statistics, which are not very informative about wave energy away from the dominant peak in the energy density spectrum.

3) The model outputs $\left(H_{m 0}, T_{p}\right)$ used here are at 3-hourly intervals, notionally representing an 'average' over that interval. Note, hourly outputs are also available from same hindcast dataset, although these require more processing as hourly data is partitioned into wind-sea and swell component.

4) The $\left(H_{m 0}, T_{p}\right)$ scatter used here sheds no light on spectral characteristics of the predicted sea-states.

5) Spectral data is included in the NOAA hindcast dataset for a subset of model cells. However, these cells are generally not in locations of interest. Spectra could be estimated using a reconstruction process, involving fitting standard spectra to partitioned 
statistics for the wind and the swell sea components included in the hindcast dataset, but this requires calibration parameters derived from the nearest cell with spectral data. This is a relatively complex procedure for estimates of spectra which remain only approximate.

6) The NOAA hindcast model is largely un-validated in Scottish waters. Marine Scotland [18] observe that the NOAA hindcast dataset "significantly underestimates wave heights ... underestimates the wave climate from the north and overestimates waves from the west-southwest".

\section{CONCLUSIONS}

Of the three sites considered, the case study suggests that the Burghead site offers the best potential to be used as a quarter-scale WEC testing site over the period May to July. The NOAA hindcast data suggests that scale seastates occur at this site in bins covering the full range of scatter table bins of interest. Melvaig Peninsula may also be acceptable during this period, though it features more sea-states which fall outside the range of the proposed commercial-scale site. Comparing these two sites with South Arran, it's clear that a site that has access to relatively long swell is necessary to get a good match with the scatter matrix of a commercial-scale site.

One consequence of having good coverage of the occurrence scatter is that the length of time available for testing in particular sea-state bins is relatively short. For example, over May to July in 2008 the \% occurrence of seastates in the $\left(7 \mathrm{~m}<H_{m 0}<8 \mathrm{~m}, 14 \mathrm{~s}<\mathrm{T}_{p}<15 \mathrm{~s}\right)$ bin was just $0.1 \%$, equivalent to this sea-state being available for testing for a total of 2 hours. Clearly, any device downtime due to faults or maintenance could result in this condition being missed.

Although the environmental conditions generally are a good match during the period of May to July, an issue with the Burghead and Melvaig Peninsula sites is that most offshore standards on design and installation of offshore structures require structures and ancillary equipment (such as moorings) to be able to withstand conditions which could occur at any time of year. Therefore, sea-states occurring outside the target range, such as those observed to occur in February to April, would need to be accounted for in design activities ordinarily.

In these cases, it may be beneficial to go to a site which is more strongly wind sea dominated (such as South Arran) and to choose the scale of the test device accordingly. The advantage of a wind sea dominated site is that the range of $\left(H_{m 0}, T_{p}\right)$ is typically constrained to a much narrower band of sea-states, ensuring that sea-state bins which are populated have a much higher frequency of occurrence.

The suitability of a potential site identified using coarse hindcast data sets should be confirmed with high resolution spectral wave modelling using an appropriately validated model (i.e with measurements) and covering enough years to make reliable estimates of extreme seastates.

A simple method of exploring whether a site has an appropriate resource for scaled open water WEC testing has been identified, and the potential of using hindcast data from a model with a relatively coarse spatial resolution to down-select sites has been explored. The case study seems to suggest that the hindcast data used offers some insight on the suitability of sites for scale testing.

Verification of these findings using spectral wave modelling with a higher spatial resolution or measurements from the site itself would be the next logical step.

\section{A. Interesting Questions Arising}

A number of interesting questions arise through this work some of which are summarized in Table IV below, with some hypothesis of what the answer to each question might be.

TABLE IV

INTERESTING QUESTIONS ARISING FROM THIS STUDY INTO SCALE SITE SELECTION

\begin{tabular}{ll}
\hline Question & Hypothesis \\
\hline $\begin{array}{l}\text { Is it possible to } \\
\text { identify scale sites }\end{array}$ & $\begin{array}{l}\text { Analysis of hindcast data in the present } \\
\text { work gives some encouragement that } \\
\text { with coarse }\end{array}$ \\
resolution spectral & $\begin{array}{l}\text { come useful insights can be gained from } \\
\text { wave models? }\end{array}$ \\
$\begin{array}{l}\text { down-selecting sites. More detailed } \\
\text { investigation on this would seem to be } \\
\text { required, particularly in respect of the } \\
\text { influence of nearshore processes. }\end{array}$
\end{tabular}

Simple metrics (such as the annual average incident wave power) are often used to select suitable commercialscale sites. Are these simple metrics available to identify suitable scale test sites?

It is assumed that the intention for the scale test site is to capture the full range of sea-states that would be exploited by commercial-scale device during scale testing. A weighted score which uses scale site \% occurrences for each scatter table bin as sub-scores and the commercial scale \% incident energy for each scatter table bin as weights for each corresponding sub-score could potentially work for this. An alternative could be to use a device's power matrix if this was available. Both merit further consideration.

Is it possible to find scale sites where the test site spectra as well as short term wave statistics are directly comparable with those at the commercial scale site?
Many documents (e.g. [9] and [10]) highlight errors which can be made when power capture is estimated using sea- state spectrum which does not represent the actual measured spectrum. This prompts questions about how representative scale site spectra are of a commercial site, and whether scale sites with more representative spectra can be found? This question is not addressed in the literature considered in this study. 
How to deal with effects arising from scaling the averaging duration of the sea statistics during scale site selection?
An often-overlooked issue is that if short term wave statistics are calculated with a specific averaging duration, this should also be Froude scaled when the sea-state statistical data are scaled. For example, if sea-state statistical data with an averaging duration of an hour is Froude scaled by 4 , the scaled-up statistical data has an averaging duration of 2 hours. This can be problematic when sea-state statistics associated with a 30-minute averaging duration at full-scale are of interest. A longer averaging duration can change the value seen in statistics. Potentially this is something which must be lived with as:

- averaging durations utilized in numerical models are often inherited from data (e.g. wind data) used to force model;

- averaging duration is used to manage the volume of data generated in a numerical modelling or measurement campaign; and

- longer averaging durations are required to model/measure some oceanic phenomena of interest to modellers (e.g. hurricane seas).

\section{REFERENCES}

[1] Marine energy - Wave, tidal and other water current converters - Part 103: Guidelines for the early stage development of wave energy converters: Best practices and recommended procedures for the testing of pre-prototype scale devices, IEC TS 62600103:2018.

[2] EMEC, information on test support buoy retrieved from EMEC website, February 2019, http://www.emec.org.uk/facilities/scale-test-sites/.

[3] L. E. Myers, A. S. Bahaj, V. Heller, C. Retzler, J. F. Dhedin, P. Ricci, O. Duperray, and J. L. Mendia, "Site matching and interaction effects", EquiMar, D5.4, 2010.

[4] L. Cradden et al., "Multi-criteria site selection for offshore renewable energy platforms", Renewable Energy, vol. 87, part 1, pp. 791-806, March 2016.

[5] Marine energy - Wave, tidal and other water current converters - Part 101: Wave energy resource assessment and characterisation, IEC TS 62600-101:2015.

[6] Natura 2000 database, January 2019, http://natura2000.eea.europa.eu

[7] Marine Traffic, AIS vessel tracking data, January 2019, www.marinetraffic.com.

[8] R. G. Dean, and R. A. Dalrymple, "Water wave mechanics for engineers and scientists", World Scientific, 1991.

[9] C. Maisondieu, and M. Le Boulluec, "Benefits of using a spectral hindcast database for wave power extraction", International Journal of Ocean and Climate Systems, vol. 7(3), pp. $83-87,2016$.

[10] M. O'Conner and B. Holmes, “Test Sites Catalogue”, EquiMar, D4.3, 2011.

[11] R. Atan et al., "Galway Bay - The 1/4 scale wave energy test site? A detailed wave energy resource assessment and investigation of scaling factors", Renewable Energy, vol. 119, pp. 217-234, April 2018.

[12] H. Smith, I. Ashton, J. Van-Nieuwkoop, D. Parish and L. Johanning, "Wave resource assessment for the Falmouth Bay

marine energy test site (FaBTest)", 4th International Conference on Ocean Energy, Dublin, Ireland, 2012.

[13] National Oceanic and Atmospheric Administration (NOAA), NCEP Wavewatch III ${ }^{\circledR}$ Hindcast and Reanalysis Archives, January 2019.

[14] J. Cruz, "WEC Classes: Preliminary Studies", in 11th European Wave and Tidal Energy Conference, Nantes, France, 2015.

[15] V. S. Neary, R. G. Coe, J. Cruz, K. Haas, G. Bacelli, Y. Debruyne, S. Ahn, and V. Nevarez "Classification Systems for Wave Energy Resources and WEC Technologies", in 12th European Wave and Tidal Energy Conference, Cork, Ireland, 2017.

[16] K. Hasselmann et al., Measurements of Wind-Wave Growth and Swell Decay During the Joint North Sea Wave Project (JONSWAP), Deutschen Hydrographischen Institut, No. 12, Hamburg, Germany, 1973

[17] Environmental conditions and environmental loads, DNVGL-RPC205, Section 3.7.2, 2017.

[18] D. Price, C. Stuiver, H. Johnson, A. Gallego, R. O'Hara Murray, "The Scottish Shelf Model. Part 2: Pentland Firth and Orkney Waters Sub-Domain", Scottish Marine and Freshwater Science, vol. 7, no. 4, 2016

[19] Wave Energy Scotland, Novel Wave Energy Converter Programme, January 2019 See www.waveenergscotland.co.uk for further details 